\title{
Transcutaneous electrical nerve stimulation, acupuncture, and spinal cord stimulation on neuropathic, inflammatory and, non- inflammatory pain in rat models
}

\author{
Karina Laurenti Sato ${ }^{1}$, Luciana Sayuri Sanada ${ }^{2}$, Morgana Duarte da Silva ${ }^{3}$, Rodrigo Okubo ${ }^{2}$, and \\ Kathleen A. Sluka ${ }^{4}$ \\ 'Department of Physical Therapy, Federal University of Sergipe, Sao Cristovao, Brazil \\ ${ }^{2}$ Department of Physical Therapy, Physiotherapy Postgraduate Program, Santa Catarina State University, Florianopolis, Brazil \\ ${ }^{3}$ Department of Physical Therapy, Federal University of Pampa, Uruguaiana, Brazil \\ ${ }^{4}$ Department of Physical Therapy and Rehabilitation Science, Pain Research Program, University of lowa, lowa City, IA, USA
}

Received October 7, 2019

Revised December 1, 2019

Accepted December 15, 2019

\section{Correspondence}

Luciana Sayuri Sanada

Department of Physical Therapy, Santa

Catarina State University, Rua Pascoal

Simone, 358 Coqueiros, Florianopolis

88080-350, Brazil

Tel: +55-48-36648627

Fax: +55-48-36648627

E-mail: luciana.sanada@udesc.br
Background: Transcutaneous electrical nerve stimulation (TENS), manual acupuncture (MA), and spinal cord stimulation (SCS) are used to treat a variety of pain conditions. These non-pharmacological treatments are often thought to work through similar mechanisms, and thus should have similar effects for different types of pain. However, it is unclear if each of these treatments work equally well on each type of pain condition. The purpose of this study was to compared the effects of TENS, MA, and SCS on neuropathic, inflammatory, and non-inflammatory pain models.

Methods: TENS $60 \mathrm{~Hz}, 200 \mu \mathrm{s}, 90 \%$ motor threshold (MT), SCS was applied at $60 \mathrm{~Hz}$, an intensity of $90 \% \mathrm{MT}$, and a 0.25 ms pulse width. MA was performed by inserting a stainless-steel needle to a depth of about 4-5 $\mathrm{mm}$ at the Sanyinjiao (SP6) and Zusanli (ST36) acupoints on a spared nerve injury (SNI), knee joint inflammation (3\% carrageenan), and non-inflammatory muscle pain (intramuscular $\mathrm{pH} 4.0$ injections) in rats. Mechanical withdrawal thresholds of the paw, muscle, and/or joint were assessed before and after induction of the pain model, and daily before and after treatment.

Results: The reduced withdrawal thresholds were significantly reversed by application of either TENS or SCS $(P<0.05)$. MA, on the other hand, increased the withdrawal threshold in animals with SNI and joint inflammation, but not chronic muscle pain.

Conclusions: TENS and SCS produce similar effects in neuropathic, inflammatory and non-inflammatory muscle pain models while MA is only effective in inflammatory and neuropathic pain models.

Key Words: Acupuncture Therapy; Inflammation; Knee Joint; Myalgia; Neuralgia; Pain; Spinal Cord Stimulation; Transcutaneous Electric Nerve Stimulation.

\section{INTRODUCTION}

Pain can be pathophysiological classified into the cat- egories: nociceptive, neuropathic, and "other pain" (that not involve apparent damage, like fibromyalgia) [1]. The spared nerve injury (SNI), used to model neuropathic pain, (c) This is an open-access article distributed under the terms of the Creative Commons Attribution Non-Commercial License (http://creativecommons.org/licenses/by-nc/4.0/), which permits unrestricted non-commercial use, distribution, and reproduction in any medium, provided the original work is properly cited.

(C) The Korean Pain Society, 2020
Author contributions: Karina Laurenti Sato: Study conception; Luciana Sayuri Sanada: Methodology; Morgana Duarte da Silva: Methodology; Rodrigo Okubo: Writing/manuscript preparation; Kathleen A. Sluka: Project administration. 
results in injury and inflammation of a peripheral nerve model [2]. Intraarticular injection of 3\% carrageenan, used to model arthritis, induces acute and chronic inflammation [3]. Repeated intramuscular acid injections, used to model chronic widespread muscle pain, is non-inflammatory, with hyperalgesia maintained by the central mechanisms [4]. The neuropathic pain and inflammatory pain models result in sensitization of nociceptors, and sensitization of central pathways in the dorsal horn of the spinal cord and supraspinal sites [5], while the non-inflammatory pain model is maintained by sensitization of central pathways in the dorsal horn and supraspinal sites $[4,6]$.

Several non-pharmacological forms of analgesic treatments are available for effective treatment of pain. Transcutaneous electrical nerve stimulation (TENS) delivers electrical current through the skin to treat pain, and is effective in several clinical conditions including those associated with inflammatory, neuropathic, and non-inflammatory pain [7]. Spinal cord stimulation (SCS), which delivers electrical current to the dorsal columns through implanted electrodes, is commonly used for the treatment of neuropathic pain. Clinical studies in patients and animal models of neuropathic pain showed that SCS reduces pain and allodynia [8-10]. Manual acupuncture (MA) is effective for treatment of several types of pain conditions in animal models and humans, including neuropathic and inflammatory pain conditions $[11,12]$. Both TENS and SCS produce analgesia through similar mechanisms, including the release of inhibitory neurotransmitters gammaaminobutyric acid (GABA), serotonin, and opioids in the central nervous system, and a reduction of central neuron sensitization [10,13-15]. Similarly, MA produces analgesia through release of serotonin, noradrenaline, and opioids, and reduces not only central sensitization [12,16-18], but also inflammation [19].

We hypothesized that TENS and SCS would have similar effects on pain behaviors in 3 different types of pain: inflammatory, neuropathic, and non-inflammation; but that acupuncture would show a different pattern. Thus, we compared the effects of TENS, SCS, and MA on neuropathic, inflammatory, and non-inflammatory pain models.

\section{MATERIALS AND METHODS}

All experiments were approved by the University of Iowa Animal Care and Use Committee and were carried out according to the guidelines of the National Institutes of Health (approval No. 1208181). Two researchers were trained to perform the experiment. One researcher was responsible for the surgeries and treatment of the animals. The other one did the behavior assessment, and he was blinded about the surgeries and treatment.

\section{Animals}

Male Sprague-Dawley rats weighing 225-300 g $(\mathrm{n}=54)$ were used in these studies. The animals were kept in a 12hour dark-light cycle with free access to standard rat food and water.

\section{Nerve injury model $(\mathrm{n}=18)$}

Rats were anesthetized with $2-3 \%$ isoflurane via a nose cone, the tibial and common peroneal nerves on one limb were tightly ligated with 4-0 silk, and the sural nerve was kept intact, as previously described [2]. The overlying muscle was sutured with 4-0 silk, and the tissue was sutured with 3-0 silk. Local anesthetic was applied to the incision.

\section{Induction of inflammation $(n=18)$}

Rats were deeply anesthetized with $2 \%-3 \%$ isoflurane via a nose cone. A solution of $3 \%$ carrageenan $(0.1 \mathrm{~mL}, \mathrm{pH} 7.4)$ in sterile saline was then injected into the left knee joint to induce inflammation.

\section{Acid saline-induced chronic muscle pain $(\mathrm{n}=18)$}

Rats were anesthetized with $2 \%-3 \%$ isoflurane a via nose cone and $20 \mu \mathrm{L}$ of sterile saline ( $\mathrm{pH} 4.0$, adjusted with $\mathrm{HCl}$ ) was injected in the left gastrocnemius muscle. This procedure was performed again 5 days after the first injection [4].

\section{Behavior tests}

All behavioral tests were done with the experimenter blinded to treatment and experimental group. A separate experimenter applied the intervention. After that, she helped the other experimenter to assess, covering the behavioral test. Behavioral tests were performed in groups of 6 animals with two animals receiving acupuncture, two receiving TENS, and two receiving SCS. Each group of 6 animals received the same injury: neuropathic pain, joint inflammation, or chronic muscle pain.

\section{Mechanical withdrawal thresholds}

All rats were acclimated to the room for 30 minutes, and to the plastic testing cage placed on an elevated wire mesh floor for 15 minutes. To test for the mechanical withdrawal thresholds of the paw, calibrated von Frey filaments (Touch test sensory evaluator, kit of 20; Stoelting Co., Wood Dale, IL) with bending forces ranging from 1 to $402 \mathrm{mN}$ were ap- 
plied to the plantar surface of the ipsilateral paw for the inflammatory and non-inflammatory models, as previously described [20-22]. For the SNI model, filaments were applied to the area innervated by the sural nerve, on the ipsilateral paw as previously described [10]. The lowest withdrawal force that produced a withdrawal was recorded as the threshold. A decrease in the mechanical withdrawal threshold of the paw is interpreted as cutaneous hyperalgesia of the paw in this study.

\section{Muscle or joint withdrawal thresholds}

Animals were acclimated to the testing room and procedures were performed 2 times per day for two days. For acclimation, rats were restrained in a gardener's glove for 5 minutes and the hind limb gently extended. To test withdrawal thresholds, the experimenter extended one hind limb, and the knee joint or gastrocnemius muscle was compressed using a pair of calibrated forceps until the animal withdrew the limb $[23,24]$. The tip of the modified forceps $\left(30 \mathrm{~mm}^{2}\right)$ was used for compression. The maximum compression force applied at withdrawal was recorded as the threshold. Three trials spaced five minutes apart were averaged to obtain one reading at each time point. A decrease in the mechanical withdrawal threshold of the paw is interpreted as muscle hyperalgesia in this study.

\section{Application of TENS}

TENS $60 \mathrm{~Hz}, 200 \mu \mathrm{s}, 90 \%$ motor threshold (MT) was administered after animals were anesthetized with $2-3 \%$ isoflurane. TENS was applied 15 minutes daily for 4 days in all three-pain models. Every day, before the application of TENS, the animals were shaved, and their skin was cleaned with $70 \%$ alcohol. Pre-gelled electrodes $(1.2 \mathrm{~cm}$ in diameter) were placed on the medial and lateral aspects of the inflamed knee joint, over the injected gastrocnemius muscle, or over the lumbar paravertebral muscles unilaterally for those with SNI. Following fifteen min of administration of TENS, rats were removed from anesthesia, the use of TENS was discontinued, and the pre-gelled electrodes were removed.

There were three TENS treatment groups: 1) the SNI group, in which all rats were anesthetized, and 4 electrodes were placed diagonally on their shaved paravertebral muscles in the lumbar region; 2) the joint inflammation group, in which all rats were anesthetized, and 2 electrodes were placed on the shaved knee joint; and 3) the chronic muscle pain group, in which all rats were anesthetized, and 2 electrodes were placed over the gastrocnemius muscle. Amplitude was determined by increasing the intensity until a visible motor contraction was elicited, defined as the MT, and then decreased to $90 \%$ of MT.

\section{Implantation of the SCS electrode}

One week before induction of the model, an epidural lead and neurostimulator were placed in the animal while the animal was deeply anesthetized with $2 \%-4 \%$ isoflurane. A small laminectomy was performed at the level of T13, which corresponds to the upper lumbar spinal cord region after nerve injury. The lead was then inserted epidurally in the rostral direction, and the neurostimulator was placed between the muscle and the skin on the left flank of the animal for connection to a neurostimulator (InterStim iCon; model 3058; Medtronic Inc., Minneapolis, MN). This allowed us to program the stimulator externally and have the animals remain in their home cages for treatment (model 8840; Medtronic Inc.) previously described [10].

A neurostimulator was placed between the muscle and the skin on the left flank. SCS was applied at $60 \mathrm{~Hz}$ frequency at an intensity of $90 \%$ of the MT and pulse width of $0.25 \mathrm{~ms}$ for 15 minutes each day. We previously showed analgesic effects with $60 \mathrm{~Hz}$ SCS at 90\% MT in animals with SNI and in animals with non-inflammatory muscle pain $[10,25]$. All parameters of stimulation were programmed into the stimulator immediately prior to the start of stimulation. The animals received SCS while awake and freely moving in their home cages.

\section{MA treatment}

Animals were acclimated to the testing room and procedures 2 times per day for two days in a gardener's glove. The experimenter extended the ipsilateral hind limb to expose the limb for needling. MA stimulation was performed by inserting a stainless-steel needle $(0.17 \times 7 \mathrm{~mm})$ to a depth of about 4-5 $\mathrm{mm}$ at the ipsilateral Sanyinjiao (SP6) and Zusanli (ST36) acupoints [12,19]. The needle was then rotated at a rate of two spins per second for $15 \mathrm{sec}$ onds each, with a total of 30 spins, and then the animals could rest with the needles still inserted for an additional 15 minutes in a transparent acrylic box (approximately $9 \times$ $7 \times 11 \mathrm{~cm}$ ). During this period, the animals were not restrained, and no anesthetic was applied. The animals remained awake and still during the treatment, and no signs of distress were observed. Acupoints SP6 and ST36 in the rats were located as described previously [26]. Behavioral measurements were conducted 30 minutes after needle withdrawal [12].

\section{Experimental design}

Table 1 shows the experimental design for each model and 
Table 1. Experimental Design Showing Treatment Parameters for Each Modality in Each Model

\begin{tabular}{|c|c|c|c|}
\hline \multirow{2}{*}{ Condition } & \multicolumn{3}{|c|}{ Treatment } \\
\hline & SCS & TENS & MA \\
\hline SNI & $\begin{array}{l}\text { Internal implantation, } 4 \text { day, } 15 \text { min } \\
\text { per day, starting } 2 \text { wk after SNI, be- } \\
\text { havior test before and after } 30 \text { min } \\
\text { treatment. }\end{array}$ & $\begin{array}{l}\text { Four electrodes on paravertebral muscle, } \\
4 \text { day, } 15 \text { min per day, starting } 2 \text { wk after } \\
\text { SNI, behavior test before and after } 30 \text { min } \\
\text { treatment. }\end{array}$ & $\begin{array}{l}\text { Two needles one on left Sanyinjiao (SP6) } \\
\text { and other on left Zusanli (ST36) acupoints, } 4 \\
\text { day, } 15 \text { min per day, starting } 2 \text { wk after SNI, } \\
\text { behavior test before and after } 30 \text { min treat- } \\
\text { ment. }\end{array}$ \\
\hline Inflammatory & $\begin{array}{l}\text { Internal implantation, } 4 \text { day, } 15 \text { min } \\
\text { per day, starting } 24 \mathrm{hr} \text { after } 3 \% \text { car- } \\
\text { rageenan injection, behavior test } \\
\text { before and after } 30 \text { min treatment. }\end{array}$ & $\begin{array}{l}\text { Two electrodes on knee joint on ipsilateral } \\
\text { side, } 4 \text { day, } 15 \text { min per day, starting } 24 \mathrm{hr} \\
\text { after } 3 \% \text { carrageenan injection, behavior } \\
\text { test before and after } 30 \text { min treatment. }\end{array}$ & $\begin{array}{l}\text { Two needles one on left SP6 and other on left } \\
\text { ST36 acupoints, } 4 \text { day, } 15 \text { min per day, } 24 \mathrm{hr} \\
\text { after } 3 \% \text { carrageenan injection, behavior test } \\
\text { before and after } 30 \text { min treatment. }\end{array}$ \\
\hline Non-inflammatory & $\begin{array}{l}\text { Internal implantation, } 4 \text { day, } 15 \text { min } \\
\text { per day, starting } 24 \mathrm{hr} \text { after second } \\
\text { injection of saline, behavior test be- } \\
\text { fore and after } 30 \text { min treatment. }\end{array}$ & $\begin{array}{l}\text { Two electrodes on gastrocnemius muscle } \\
\text { on ipsilateral side, } 4 \text { day, } 15 \text { min per day, } \\
\text { starting } 24 \mathrm{hr} \text { after second injection of sa- } \\
\text { line, behavior test before and after } 30 \text { min } \\
\text { treatment. }\end{array}$ & $\begin{array}{l}\text { Two needles one on left SP } 6 \text { and other on left } \\
\text { ST36 acupoints, } 4 \text { day, } 15 \text { min per day, } 24 \mathrm{hr} \\
\text { after second injection of saline, behavior test } \\
\text { before and after } 30 \text { min treatment. }\end{array}$ \\
\hline
\end{tabular}

SCS: spinal cord stimulation, TENS: transcutaneous electrical nerve stimulation, MA: manual acupuncture, SNI: spared nerve injury.

treatment. Briefly, animals were tested behaviorally before and after induction of the model, and before and after treatment daily for 4-days. Treatments were in separate animals starting 2-weeks after SNI, 24 hours after joint inflammation, or 24 hours after induction of non-inflammatory pain.

\section{Data analysis}

For the mechanical withdrawal threshold of the paw, and for the mechanical withdrawal thresholds of the muscle, differences between groups (different pain models and different treatments) were tested with a repeated measures ANOVA with dependent variables of time (before the pain models, before and after treatment each day) and side (ipsilateral and contralateral), and with the independent variable of intervention (MA, TENS, and SCS).

The parametric paired $t$-test was used to analyze changes in the mechanical withdrawal threshold of the hind paw (all pain models) and the calibrated forceps (knee joint withdrawal threshold and muscle withdrawal threshold) at each time point (before and after treatment on the same day). Post hoc testing between groups was performed with a Tukey's test. A $P$ value of $<0.05$ was considered significant. Analysis of the data was performed using SPSS Statistics ver. 19.0 (IBM Corp., Armonk, NY).

\section{RESULTS}

When compared to the baseline, there was a decrease in the paw withdrawal threshold two weeks after the nerve injury, the paw and joint withdrawal thresholds 2-4 hours after joint inflammation, and the paw and muscle withdrawal thresholds decreased 24 hours after the second acid injection (Figs. 1, 2). There were no changes in withdrawal thresholds contralaterally in the neuropathic or joint inflammation model (data not shown); significant decreases from the baseline occurred for the withdrawal threshold contralaterally in the non-inflammatory pain model.

\section{Effects of treatment in neuropathic pain}

In the SNI model (Table 2; lines SNI/left and right paw), the decreased withdrawal thresholds of the paw ipsilaterally were significantly increased by TENS, SCS, and MA immediately after treatment on each day (time effect; $\mathrm{F}_{8,120}$ $=15.0, P<0.001)$. The effect of TENS, SCS, and MA on the withdrawal thresholds of the paw was lost 24 hours after treatment prior to the next treatment. A significant effect occurred for the side, with the ipsilateral side showing significant decreases in withdrawal threshold compared to the contralateral side (side effect; $\mathrm{F}_{1,120}=276, P<0.001$ ). There was no difference for intervention, i.e., between SCS, TENS and MA (Fig. 1A).

\section{Effects of treatment in joint inflammation}

In the joint inflammation model, there were significant differences for time $\left(\mathrm{F}_{8,120}=31.6, P<0.001\right)$, for side $\left(\mathrm{F}_{1,120}=\right.$ $3,014, P<0.001$ ), and for the withdrawal thresholds (Table 2; lines Inf/left and right paw) of the paw. Joint inflammation reduced withdrawal thresholds ipsilaterally, and these 

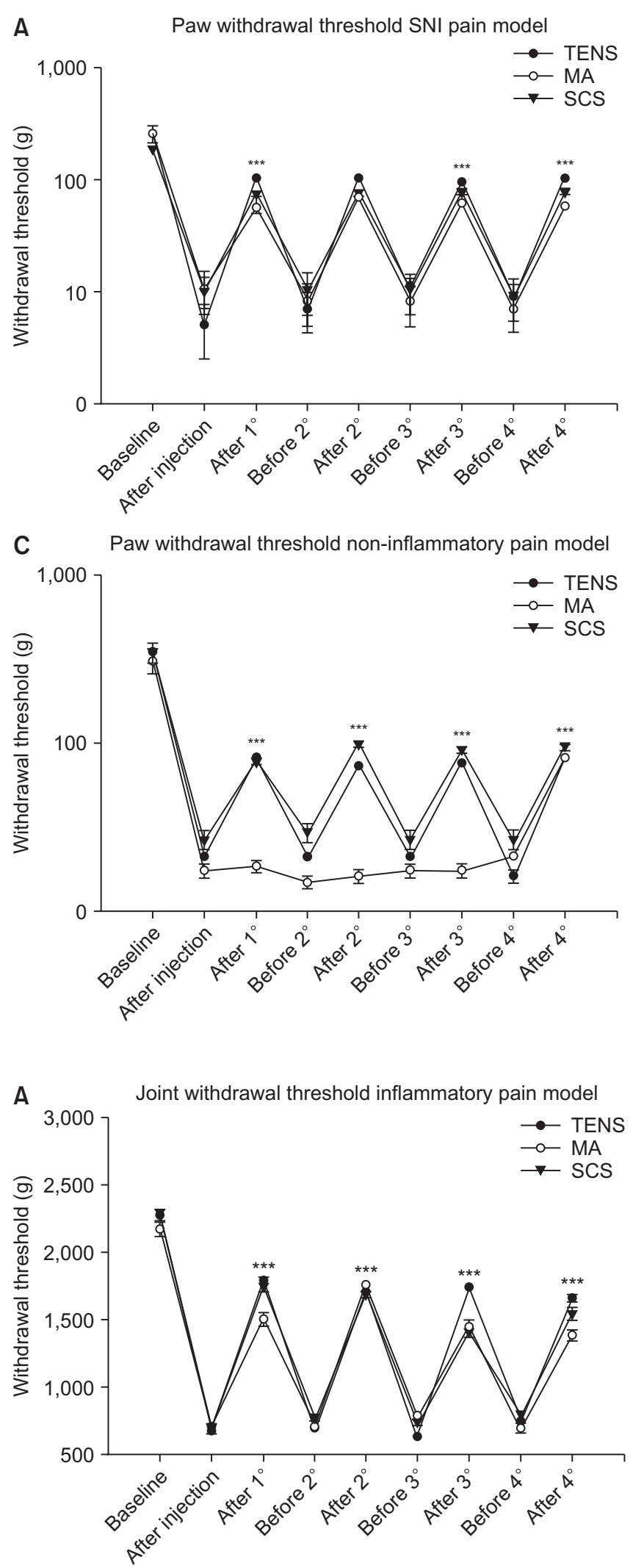

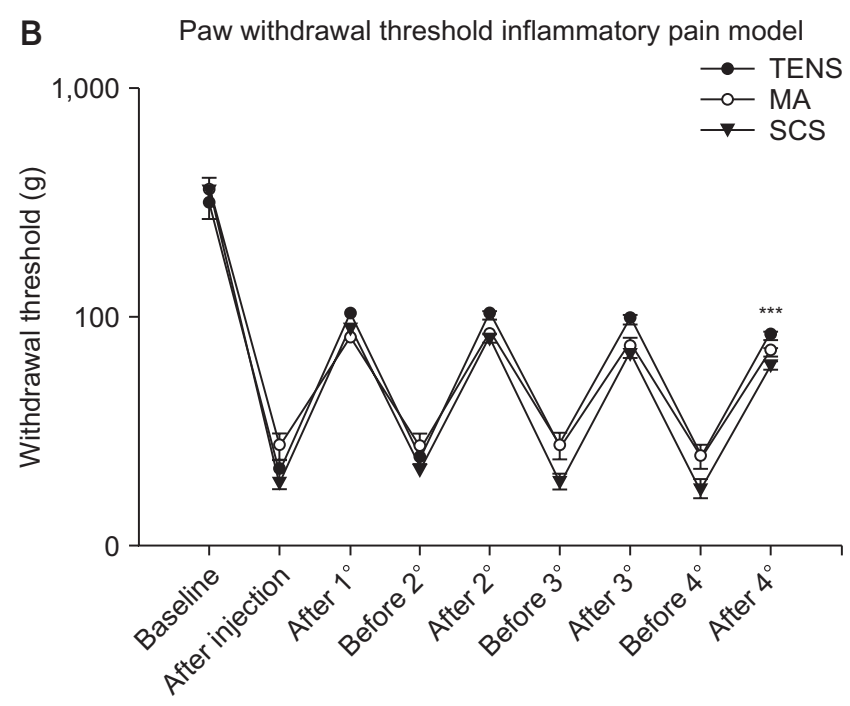

Fig. 1. Average paw withdrawal thresholds in the SNI group (A), joint inflammation group (B), and the non-inflammatory muscle pain group (C). Each graph shows the effects before and after induction of the model, and before and after treatment on each day. A significant decrease in withdrawal thresholds occurred after induction of the models, and this reduced withdrawal thresholds was increased after treatment on each day for the SNI and the joint inflammation model. For the acid model, a significant decrease occurred in all groups, and this decreased threshold was reversed by TENS and SCS but not by MA. SNI: spared nerve injury, TENS: transcutaneous electrical nerve stimulation, SCS: spinal cord stimulation, MA: manual acupuncture. $* * * P<0.001$.

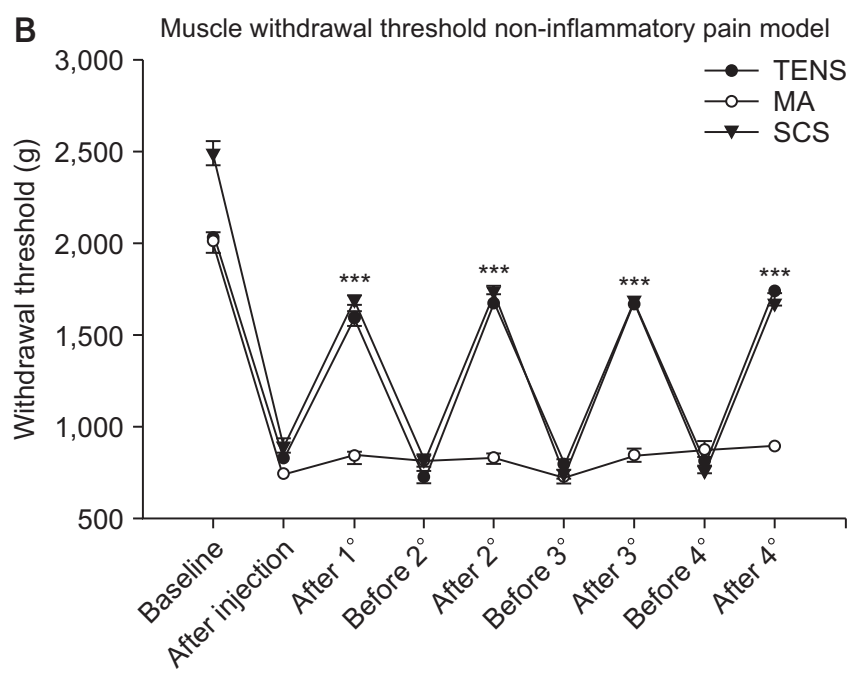

Fig. 2. (A) Average joint withdrawal thresholds before (baseline) and after induction of knee joint inflammation, and before and after treatment on each day with TENS, MA, or SCS. Significant increases occurred after treatment on each day. TENS was significantly higher than SCS and MA. (B) Average

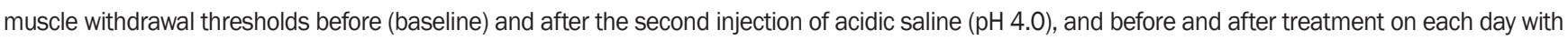
TENS, MA, SCS. Significant increases occurred after treatment on each day. SCS and TENS were significantly greater than MA. TENS: transcutaneous electrical nerve stimulation, MA: manual acupuncture, SCS: spinal cord stimulation. $* * * P<0.001$. 
Table 2. Average Paw Withdrawal Thresholds in the Groups Before and After Induction of the Model, and Before and After Treatment on Each Day

\begin{tabular}{|c|c|c|c|c|c|c|c|c|c|}
\hline \multirow{2}{*}{ Group } & \multirow{2}{*}{$\begin{array}{c}\text { Baseline } \\
\text { (g) }\end{array}$} & \multicolumn{2}{|c|}{ Day 1} & \multicolumn{2}{|c|}{ Day 2} & \multicolumn{2}{|c|}{ Day 3} & \multicolumn{2}{|c|}{ Day 4} \\
\hline & & Pre (g) & Post (g) & Pre (g) & Post (g) & Pre (g) & Post (g) & Pre (g) & Post (g) \\
\hline \multicolumn{10}{|l|}{ Left paw } \\
\hline SNI-TENS & $259 \pm 45$ & $5 \pm 3^{a}$ & $103 \pm 4^{\mathrm{ab}}$ & $7 \pm 3^{a}$ & $103 \pm 4^{\mathrm{ab}}$ & $11 \pm 2^{\mathrm{a}}$ & $95 \pm 5^{\mathrm{ab}}$ & $9 \pm 3^{a}$ & $103 \pm 4^{\mathrm{ab}}$ \\
\hline SNI-SCS & $188 \pm 0$ & $10 \pm 3^{\mathrm{a}}$ & $75 \pm 4^{\mathrm{ab}}$ & $11 \pm 4^{\mathrm{a}}$ & $75 \pm 4^{\mathrm{ab}}$ & $11 \pm 4^{\mathrm{a}}$ & $78 \pm 3^{\mathrm{ab}}$ & $9 \pm 4^{a}$ & $78 \pm 3^{\mathrm{ab}}$ \\
\hline SNIIMA & $259 \pm 45$ & $11 \pm 4^{\mathrm{a}}$ & $56 \pm 5^{\mathrm{ab}}$ & $8 \pm 3^{a}$ & $70 \pm 3^{\mathrm{ab}}$ & $8 \pm 3^{a}$ & $61 \pm 4^{\mathrm{ab}}$ & $7 \pm 3^{a}$ & $58 \pm 4^{\mathrm{ab}}$ \\
\hline \multicolumn{10}{|l|}{ Right paw } \\
\hline SNI-TENS & $366 \pm 66$ & $402 \pm 0$ & $402 \pm 0$ & $402 \pm 0$ & $366 \pm 36$ & $366 \pm 36$ & $366 \pm 36$ & $366 \pm 36$ & $366 \pm 36$ \\
\hline SNI-SCS & $259 \pm 45$ & $366 \pm 36$ & $400 \pm 0$ & $331 \pm 45$ & $366 \pm 36$ & $331 \pm 45$ & $331 \pm 45$ & $331 \pm 45$ & $390 \pm 47$ \\
\hline SNIIMA & $331 \pm 45$ & $331 \pm 45$ & $331 \pm 45$ & $331 \pm 45$ & $366 \pm 36$ & $331 \pm 45$ & $331 \pm 45$ & $295 \pm 48$ & $295 \pm 48$ \\
\hline \multicolumn{10}{|l|}{ Left paw } \\
\hline Inf-TENS & $295 \pm 48$ & $20 \pm 0^{a}$ & $95 \pm 5^{\mathrm{ab}}$ & $23 \pm 3^{b}$ & $95 \pm 5^{\mathrm{ab}}$ & $25 \pm 3^{a}$ & $91 \pm 5^{\mathrm{ab}}$ & $23 \pm 3^{a}$ & $78 \pm 3^{\mathrm{abc}}$ \\
\hline Inf-SCS & $331 \pm 45$ & $18 \pm 1^{\mathrm{a}}$ & $75 \pm 4^{\mathrm{ab}}$ & $20 \pm 0^{b}$ & $69 \pm 5^{\mathrm{ab}}$ & $18 \pm 1^{a}$ & $61 \pm 4^{\mathrm{ab}}$ & $17 \pm 2^{\mathrm{a}}$ & $58 \pm 4^{\mathrm{ab}}$ \\
\hline Inf-MA & $331 \pm 45$ & $25 \pm 3^{a}$ & $75 \pm 4^{\mathrm{ab}}$ & $25 \pm 3^{b}$ & $78 \pm 3^{\mathrm{ab}}$ & $25 \pm 3^{a}$ & $69 \pm 5^{a b}$ & $23 \pm 3^{a}$ & $66 \pm 6^{\mathrm{ab}}$ \\
\hline \multicolumn{10}{|l|}{ Right paw } \\
\hline Inf-TENS & $331 \pm 45$ & $402 \pm 0$ & $402 \pm 0$ & $366 \pm 36$ & $366 \pm 36$ & $402 \pm 0$ & $402 \pm 0$ & $402 \pm 0$ & $402 \pm 0$ \\
\hline Inf-SCS & $366 \pm 36$ & $366 \pm 36$ & $402 \pm 0$ & $40 \pm 0$ & $402 \pm 0$ & $402 \pm 0$ & $402 \pm 0$ & $402 \pm 0$ & $402 \pm 0$ \\
\hline Inf-MA & $366 \pm 36$ & $331 \pm 45$ & $402 \pm 0$ & $402 \pm 0$ & $402 \pm 0$ & $402 \pm 0$ & $402 \pm 0$ & $402 \pm 0$ & $402 \pm 0$ \\
\hline \multicolumn{10}{|l|}{ Left paw } \\
\hline NInf-TENS & $331 \pm 45$ & $20 \pm 0^{a}$ & $78 \pm 3^{\mathrm{ab}}$ & $18 \pm 1^{a}$ & $70 \pm 3^{\mathrm{ab}}$ & $20 \pm 0^{\mathrm{a}}$ & $72 \pm 3^{\mathrm{ab}}$ & $15 \pm 1^{a}$ & $78 \pm 3^{\mathrm{ab}}$ \\
\hline NInf-SCS & $331 \pm 45$ & $25 \pm 3^{a}$ & $75 \pm 4^{\mathrm{ab}}$ & $28 \pm 4^{a}$ & $95 \pm 5^{\mathrm{ab}}$ & $25 \pm 3^{a}$ & $87 \pm 4^{\mathrm{ab}}$ & $5 \pm 3^{\mathrm{ac}}$ & $91 \pm 5^{\mathrm{ab}}$ \\
\hline NInf-MA & $295 \pm 48$ & $17 \pm 2^{\mathrm{a}}$ & $20 \pm 0^{\mathrm{a}}$ & $14 \pm 1^{\mathrm{a}}$ & $15 \pm 1^{a}$ & $17 \pm 2^{\mathrm{a}}$ & $17 \pm 2^{\mathrm{a}}$ & $20 \pm 0^{a}$ & $20 \pm 0^{a}$ \\
\hline \multicolumn{10}{|l|}{ Right paw } \\
\hline NInf-TENS & $402 \pm 0$ & $259 \pm 45$ & $295 \pm 48$ & $224 \pm 36$ & $224 \pm 36$ & $188 \pm 0$ & $188 \pm 0$ & $188 \pm 0$ & $188 \pm 0$ \\
\hline NInf-SCS & $331 \pm 45$ & $331 \pm 45$ & $331 \pm 45$ & $331 \pm 45$ & $331 \pm 45$ & $331 \pm 45$ & $331 \pm 45$ & $331 \pm 45$ & $331 \pm 45$ \\
\hline NInf-MA & $331 \pm 45$ & $224 \pm 36$ & $224 \pm 36$ & $188 \pm 0$ & $188 \pm 0$ & $188 \pm 0$ & $188 \pm 0$ & $188 \pm 0$ & $188 \pm 0$ \\
\hline
\end{tabular}

Values are presented as mean \pm standard deviation.

SNI: spared nerve injury, TENS: transcutaneous electrical nerve stimulation, SCS: spinal cord stimulation, MA: manual acupuncture, Inf: inflammatory, NInf: non-inflammatory.

${ }^{a}$ Significant statistical differences compared to contralateral (right) side $(P<0.05)$. ${ }^{b}$ Significant statistical differences in comparison to pre-immediate $(P<$ $0.05)$. ${ }^{\circ}$ Significant statistical differences in comparison a day before $(P<0.05)$.

reduced paw withdrawal thresholds were increased significantly by TENS, SCS, and MA after the first treatment; similar increases were observed after each treatment $(P$ $<0.001$ ). No significant difference between interventions was found for the withdrawal threshold of the paw (Fig. 1B).

For the joint withdrawal thresholds on the knee (Table 3; lines Inf/left and right paw), there were significant effects for time $\left(\mathrm{F}_{8,120}=275, P<0.001\right)$, for side $\left(\mathrm{F}_{1,120}=8,677\right.$, $P<0.001)$, and for intervention $\left(\mathrm{F}_{1,115}=275, P<0.001\right)$. The threshold for the ipsilateral paw was significantly less than the contralateral paw. Induction of joint inflammation reduced the withdrawal thresholds of the paw ipsilaterally, and these reduced withdrawal thresholds were increased by TENS, SCS, and MA $(P<0.001)$. There was a significant interaction between time, side, and group $\left(\mathrm{F}_{1,15}=10.3286\right.$, $P=0.001)$. Specifically, the withdrawal thresholds after treatment with TENS were significantly greater than those after SCS $(P=0.01)$ and after MA $(P<0.001)$; there were no differences between SCS and MA (Fig. 2A).

\section{Effects of treatment in non-inflammatory muscle pain}

In chronic muscle pain model, there were significant decreases in withdrawal thresholds (Table 2; lines NInf/left and right paw) of the paw after induction of the model. Both TENS and SCS significantly reversed this decrease (time effect; $\mathrm{F}_{8,120}=84, P<0.001$ ). There were significant effects related to the side, with the ipsilateral side showing greater decreases than the contralateral side $\left(\mathrm{F}_{1,120}=189\right.$, $P<0.001)$. A significant effect for intervention occurred (group effect; $\mathrm{F}_{2,15}=6.5, P=0.005$ ), and there was a significant interaction between time, side, and intervention $\left(\mathrm{F}_{16,120}=\right.$ $2.2, P=0.009)$. There was no effect of MA on paw withdrawal thresholds in the non-inflammatory pain model (Fig. 1C), with the MA group showing lower withdrawal thresholds than the TENS $(P=0.093)$ and the SCS $(P=0.008)$ groups.

For the muscle withdrawal thresholds (Table 3; lines $\mathrm{NInf} /$ left and right paw), there were significant effects for time $\left(\mathrm{F}_{8,120}=387, P<0.001\right)$, for side $\left(\mathrm{F}_{1,120}=22.505, P=\right.$ 
Table 3. Average Joint (Inflammatory Model) and Muscle (Non-inflammatory Model) Withdrawal Joint Inflammation, and the Non-inflammatory Muscle Pain Group Before and After Induction of the Model, and Before and After Treatment on Each Day

\begin{tabular}{|c|c|c|c|c|c|c|c|c|c|}
\hline \multirow{2}{*}{ Group } & \multirow{2}{*}{$\begin{array}{l}\text { Baseline } \\
\text { (g) }\end{array}$} & \multicolumn{2}{|c|}{ Day 1} & \multicolumn{2}{|c|}{ Day 2} & \multicolumn{2}{|c|}{ Day 3} & \multicolumn{2}{|c|}{ Day 4} \\
\hline & & Pre (g) & Post (g) & Pre (g) & Post (g) & Pre (g) & Post (g) & Pre (g) & Post (g) \\
\hline \multicolumn{10}{|l|}{ Left leg } \\
\hline Inf-TENS & $2,251 \pm 41$ & $590 \pm 33^{\mathrm{a}}$ & $1,739 \pm 31^{\mathrm{ab}}$ & $605 \pm 28^{a}$ & $1,651 \pm 21^{\mathrm{ab}}$ & $535 \pm 22^{a}$ & $1,688 \pm 15^{\mathrm{ab}}$ & $667 \pm 29$ & $1,405 \pm 21^{\mathrm{ab}}$ \\
\hline Inf-SCS & $2,224 \pm 24$ & $609 \pm 16^{a}$ & $1,694 \pm 37^{\mathrm{ab}}$ & $684 \pm 25^{a}$ & $1,636 \pm 26^{\mathrm{ab}}$ & $644 \pm 22^{a}$ & $1,317 \pm 21^{\mathrm{ab}}$ & $707 \pm 19$ & $1,487 \pm 50^{a b}$ \\
\hline Inf-MA & $2,139 \pm 51$ & $616 \pm 28^{a}$ & $1,443 \pm 51^{\mathrm{ab}}$ & $615 \pm 14^{a}$ & $1,709 \pm 34^{\mathrm{abc}}$ & $699 \pm 12^{a}$ & $1,384 \pm 139^{a b}$ & $601 \pm 39$ & $1,219 \pm 15^{a b}$ \\
\hline \multicolumn{10}{|l|}{ Right leg } \\
\hline Inf-TENS & $2,372 \pm 60$ & $2,437 \pm 16$ & $2,305 \pm 24$ & $2,215 \pm 25$ & $2,313 \pm 51$ & $2,264 \pm 15$ & $2,380 \pm 94$ & $2,157 \pm 28$ & $2,200 \pm 37$ \\
\hline Inf-SCS & $2,250 \pm 47$ & $2,207 \pm 25$ & $2,262 \pm 29$ & $2,113 \pm 40$ & $2,137 \pm 98$ & $2,201 \pm 43$ & $2,131 \pm 28$ & $2,057 \pm 26$ & $2,150 \pm 108$ \\
\hline Inf-MA & $2,526 \pm 93$ & $2,450 \pm 61$ & $2,520 \pm 63$ & $2,193 \pm 39$ & $2,174 \pm 26$ & $2,300 \pm 42$ & $2,204 \pm 49$ & $2,024 \pm 157$ & $2,179 \pm 25$ \\
\hline \multicolumn{10}{|l|}{ Left leg } \\
\hline NInf-TENS & $1,993 \pm 12$ & $744 \pm 18^{a}$ & $1,536 \pm 40^{\mathrm{ab}}$ & $636 \pm 31^{a}$ & $1,624 \pm 18^{\mathrm{ab}}$ & $700 \pm 35^{a}$ & $1,612 \pm 15^{\mathrm{ab}}$ & $728 \pm 24$ & $1,474 \pm 20^{a b c}$ \\
\hline NInf-SCS & $2,474 \pm 70$ & $812 \pm 42^{a}$ & $1,642 \pm 25^{a b}$ & $733 \pm 8^{\mathrm{a}}$ & $1,687 \pm 13^{\mathrm{ab}}$ & $652 \pm 24^{\mathrm{a}}$ & $1,635 \pm 20^{\mathrm{ab}}$ & $676 \pm 14$ & $1,479 \pm 10^{\mathrm{abc}}$ \\
\hline NInf-MA & $1,968 \pm 56$ & $655 \pm 12^{\mathrm{a}}$ & $752 \pm 40^{a}$ & $726 \pm 30^{a}$ & $740 \pm 30^{a}$ & $638 \pm 40^{a}$ & $758 \pm 31^{a}$ & $790 \pm 41$ & $807 \pm 16^{a}$ \\
\hline \multicolumn{10}{|l|}{ Right leg } \\
\hline NInf-TENS & $2,045 \pm 65$ & $2,142 \pm 38$ & $2,043 \pm 21$ & $2,137 \pm 18$ & $2,086 \pm 13$ & $2,030 \pm 22$ & $2,095 \pm 24$ & $2,039 \pm 25$ & $2,060 \pm 19$ \\
\hline NInf-SCS & $364 \pm 71$ & $1,975 \pm 15$ & $1,991 \pm 7$ & $1,963 \pm 12$ & $1,983 \pm 4$ & $2,011 \pm 8$ & $1,994 \pm 6$ & $1,964 \pm 13$ & $1,993 \pm 17$ \\
\hline NInf-MA & $2,107 \pm 63$ & $2,187 \pm 28$ & $2,141 \pm 34$ & $2,112 \pm 30$ & $2,056 \pm 32$ & $2,048 \pm 22$ & $1,977 \pm 48$ & $2,028 \pm 31$ & $2,060 \pm 28$ \\
\hline
\end{tabular}

Values are presented as mean \pm standard deviation.

Inf: inflammatory, TENS: transcutaneous electrical nerve stimulation, SCS: spinal cord stimulation, MA: manual acupuncture, NInf: non-inflammatory.

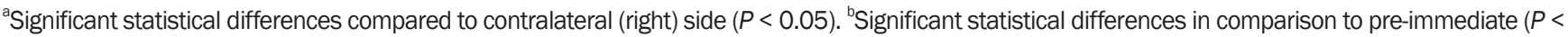
0.05). ${ }^{\circ}$ Significant statistical differences in comparison a day before $(P<0.05)$.

Table 4. Summary of Mechanisms for SCS, TENS, and MA

\begin{tabular}{cc}
\hline Type of treatment & Mechanism \\
\hline SCS & $\begin{array}{c}\text { Utilizes several neurotransmitters and their receptors including serotonin, opioids, GABA and acetylcholine, inhibits release of } \\
\text { glutamate and aspartate, and reduces glial cell activation. }\end{array}$ \\
TENS & $\begin{array}{c}\text { Activates } \delta \text {-opioid receptors, PAG, RVM, spinal inhibitory pathways, GABA, and reduces dorsal horn sensitization, glutamate, and } \\
\text { substance P release. }\end{array}$ \\
MA & Activates descendent inhibitory pathways, releases ATP peripherally, alters inflammation and immune cell phenotype.
\end{tabular}

SCS: spinal cord stimulation, TENS: transcutaneous electrical nerve stimulation, MA: manual acupuncture, GABA: gamma-aminobutyric acid, PAG: periaqueductal gray, RVM: rostral ventromedial medulla, ATP: adenosine triphosphate.

0.001), and a significant interaction between time, side, and group $\left(\mathrm{F}_{16,120}=31.6, P<0.001\right)$. Specifically, the withdrawal thresholds decreased ipsilaterally after induction of the model, and these withdrawal thresholds were reversed by TENS and SCS, but not by MA (Fig. 2B). The muscle withdrawal thresholds of the paw were lower in the MA groups than those of the TENS $(P<0.001)$ and SCS $(P<$ 0.001 ) groups; MA had no effect on the withdrawal thresholds after repeated acid injections into the muscle.

\section{DISCUSSION}

The current study compared the effects of three different types of non-pharmacological treatments (TENS, SCS, MA) for three different types of pain (neuropathic, inflamma- tory, and non-inflammatory). MA was only effective in the neuropathic and inflammatory models, while TENS and SCS were effective in all 3 models. The analgesic effects of TENS, SCS, and MA involve complex neuronal processes that utilize multiple neurotransmitters and modulators (see Table 4 for a summary), including opioid peptides and serotonin. The differences between interventions found in the current study could be explained by the different mechanisms of action used by each type of treatment.

It is known that TENS activates central inhibitory pathways to reduce hyperalgesia [14,27]. Prior studies have shown the good effects of TENS in models of joint, paw, and muscle inflammation $[13,27,28]$, analgesia lasting for 12-24 hours [21], and repetitive use producing analgesic tolerance at the central opioid receptors. Specifically, TENS reduces central neuron sensitization, and activates 
opioid, serotonin, GABA, and muscarinic receptors in the spinal cord and supraspinal pathways $[13,14,21,27,28]$. In experimental studies on neuropathic pain, TENS reduces allodynia and hyperalgesia, and there is a reduction in central neuron sensitization and glial cell activity [29]. However, little is known about the effects of TENS in the non-inflammatory model. It is thought that pain may be alleviated by using electrical stimulation directly over the area of pain (inflammatory or non-inflammatory). This peripheral stimulation induces electrical activity which inhibits the brain's perception of pain. The 'gate control theory' of Wall and Melzack is based on the principle that there is a gateway in the dorsal horn of the spinal cord, which somehow controls or regulates the flow of pain messages that are then sent to (ascending) and from (descending) higher levels of the brain for central processing, thus reducing the perception of pain $[30,31]$. Other postulated mechanisms of the pain relief mediated by TENS include the promotion of endorphin release in the brain [32] and local dilatation of blood vessels in injured tissue [33]. Clinically, TENS is effective for pain conditions associated with neuropathic pain, inflammatory pain, and non-inflammatory pain such as reducing phantom pain [34], diabetic peripheral neuropathy [35], postoperative pain [36], spinal nerve injury [37], trigeminal neuralgia [38], osteoarthritis [39], chronic musculoskeletal pain [40], and fibromyalgia [7]. Thus, TENS is effective for a variety of pain conditions with different underlying tissue pathologies.

The field of SCS also owes its inception to the concept of gate control theory, which proposed that "control of pain may be achieved by selectively activating the large, rapidly conducting fibers" [41] and can be used in inflammatory pain, although chronic pain is the main target. Conventional SCS activates large $A_{\beta}$ dorsal column axons. This activation can be measured as action potentials propagated antidromically in the peripheral nerves [42]. Electrical stimulation alters the membrane potential of neurons and other cell types exposed to electric fields, thereby altering the electrochemical properties of the segments affected [43]. Electrophysiology and molecular biology have provided a view of the effect of SCS on neurotransmitters and their receptors, which have led to the formulation of segmental and supraspinal mechanisms. The literature supports the involvement of glial cells in chronic pain and their characteristic response to electrical fields [43].

The current study showed that MA reduces hyperalgesia in the neuropathic and inflammatory pain models. However, it did not reduce hyperalgesia in the noninflammatory pain model used in the current study. Prior work shows that MA using the SP6 and ST36 acupoints has an analgesic effect that lasts up to two hours [12], produces a cumulative effect [19], and reduces hyperalgesia in neuropathic [44] and inflammatory pain models [19,26]. Neurophysiological mechanisms, by which MA exerts its analgesic effects, show activation of both peripheral and central mechanisms. Centrally, MA activates the descending inhibitory systems $[18,45]$ using opioids and serotonin in both inflammatory and neuropathic pain models $[12,16,17]$. Peripherally, MA releases adenosine triphosphate which converts to adenosine and activates the adenosine Al receptor in inflammatory pain [46]. MA, however, also promotes the resolution of inflammation. Specifically, our prior studies show that MA reduces muscle inflammation, measured by reduced inflammatory cell infiltration, vascular permeability, neutrophilic activity, and edema $[19,26]$. Further, MA has a direct effect on the immune system, increasing release of the antiinflammatory cytokine interleukin (IL)-10 and producing a phenotypic switch in the macrophage phenotype, to an increased M2 phenotype (IL-10 source) and a reduced M1 phenotype in the inflamed muscle [26]. Thus, the lack of effect on the non-inflammatory pain model may be related to the actions of MA on inflammation observed after nerve injury and injection of carrageenan. Surprisingly, however, there was not a sustained effect on nociceptive behaviors.

We speculate that while inflammation was reduced, it was not eliminated, and thus, inflammatory mediators could continue to activate nociceptors to produce nociceptive behaviors. Clinically, MA is effective in a variety of pain conditions, including neuropathic pain [47], knee osteoarthritis [45,48,49], acute and chronic back pain [49], and fibromyalgia [50]; however, there is a large variability in the acupoints used. Thus, it is possible that a different protocol of MA would be more effective in each of these different models.

Potential limitations of our study were the methods of the pain models. The variability of these methods, although not big, may be avoided in the future by using most precise ones. Also, we suggest that the protocols using different parameters of frequency, and alternating currents investigated with other methodologies should be included. Future basic science studies need to understand the different mechanisms between treatments in different models, and future clinical studies need to confirm animal data to provide a solid evidence base for the use of SCS, TENS, and MA.

The present study examined the efficacy of TENS, SCS, and MA on the neuropathic, inflammatory, and noninflammatory models of pain. While all 3 interventions were successful on minimizing pain on neuropathic and inflammatory models, only TENS and SCS were effective with the non-inflammatory pain model. These data suggest that MA may not be useful for non-inflammatory 
pain, while all 3 interventions could be used for neuropathic and inflammatory pain.

\section{CONFLICT OF INTEREST}

No potential conflict of interest relevant to this article was reported.

\section{FUNDING}

No funding to declare.

\section{ORCID}

Karina Laurenti Sato, https://orcid.org/0000-0003-3641-1832 Luciana Sayuri Sanada, https://orcid.org/0000-0002-6530-6831 Morgana Duarte da Silva, https://orcid.org/0000-0002-2487-236X Rodrigo Okubo, https://orcid.org/0000-0003-3450-2183

Kathleen A. Sluka, https://orcid.org/0000-0003-0207-8728

\section{REFERENCES}

1. Orr PM, Shank BC, Black AC. The role of pain classification systems in pain management. Crit Care Nurs Clin North Am 2017; 29: 407-18.

2. Decosterd I, Woolf CJ. Spared nerve injury: an animal model of persistent peripheral neuropathic pain. Pain 2000; 87: 14958.

3. Radhakrishnan R, Moore SA, Sluka KA. Unilateral carrageenan injection into muscle or joint induces chronic bilateral hyperalgesia in rats. Pain 2003; 104: 567-77.

4. Sluka KA, Kalra A, Moore SA. Unilateral intramuscular injections of acidic saline produce a bilateral, long-lasting hyperalgesia. Muscle Nerve 2001; 24: 37-46.

5. Lee JB, Choi SS, Ahn EH, Hahm KD, Suh JH, Leem JG, et al. Effect of perioperative perineural injection of dexamethasone and bupivacaine on a rat spared nerve injury model. Korean J Pain 2010; 23: 166-71.

6. Radhakrishnan R, Bement MK, Skyba D, Sluka KA, Kehl LJ. Models of muscle pain: carrageenan model and acidic saline model. Curr Protoc Pharmacol 2004; 25: 5.35.1-28.

7. Dailey DL, Rakel BA, Vance CG, Liebano RE, Amrit AS, Bush $\mathrm{HM}$, et al. Transcutaneous electrical nerve stimulation reduces pain, fatigue and hyperalgesia while restoring central inhibition in primary fibromyalgia. Pain 2013; 154: 2554-62.

8. Beyaz SG, Bal NŞ. Spinal cord stimulation for a patient with neuropathic pain related to congenital syringomyelia. Korean J Pain 2017; 30: 229-30.
9. Lee SJ, Yoo YM, You JA, Shin SW, Kim TK, Abdi S, et al. Successful removal of permanent spinal cord stimulators in patients with complex regional pain syndrome after complete relief of pain. Korean J Pain 2019; 32: 47-50.

10. Sato KL, Johanek LM, Sanada LS, Sluka KA. Spinal cord stimulation (SCS) improves decreased physical activity induced by nerve injury. Behav Neurosci 2014; 128: 625-32.

11. Ezzo J, Hadhazy V, Birch S, Lao L, Kaplan G, Hochberg M, et al. Acupuncture for osteoarthritis of the knee: a systematic review. Arthritis Rheum 2001; 44: 819-25.

12. Cidral-Filho FJ, da Silva MD, Moré AO, Córdova MM, Werner MF, Santos AR. Manual acupuncture inhibits mechanical hypersensitivity induced by spinal nerve ligation in rats. Neuroscience 2011; 193: 370-6.

13. Kalra A, Urban MO, Sluka KA. Blockade of opioid receptors in rostral ventral medulla prevents antihyperalgesia produced by transcutaneous electrical nerve stimulation (TENS). J Pharmacol Exp Ther 2001; 298: 257-63.

14. Maeda Y, Lisi TL, Vance CG, Sluka KA. Release of GABA and activation of GABA(A) in the spinal cord mediates the effects of TENS in rats. Brain Res 2007; 1136: 43-50.

15. Song Z, Ansah OB, Meyerson BA, Pertovaara A, Linderoth B. Exploration of supraspinal mechanisms in effects of spinal cord stimulation: role of the locus coeruleus. Neuroscience 2013; 253: 426-34.

16. Takeshige C, Sato T, Mera T, Hisamitsu T, Fang J. Descending pain inhibitory system involved in acupuncture analgesia. Brain Res Bull 1992; 29: 617-34.

17. Mayer DJ. Biological mechanisms of acupuncture. Prog Brain Res 2000; 122: 457-77.

18. Zhao ZQ. Neural mechanism underlying acupuncture analgesia. Prog Neurobiol 2008; 85: 355-75.

19. da Silva MD, Bobinski F, Sato KL, Kolker SJ, Sluka KA, Santos AR. IL-10 cytokine released from M2 macrophages is crucial for analgesic and anti-inflammatory effects of acupuncture in a model of inflammatory muscle pain. Mol Neurobiol 2015; 51: 19-31.

20. Chaplan SR, Bach FW, Pogrel JW, Chung JM, Yaksh TL. Quantitative assessment of tactile allodynia in the rat paw. J Neurosci Methods 1994; 53: 55-63.

21. Sluka KA. Blockade of N- and P/Q-type calcium channels reduces the secondary heat hyperalgesia induced by acute inflammation. J Pharmacol Exp Ther 1998; 287: 232-7.

22. Gopalkrishnan P, Sluka KA. Effect of varying frequency, intensity, and pulse duration of transcutaneous electrical nerve stimulation on primary hyperalgesia in inflamed rats. Arch Phys Med Rehabil 2000; 81: 984-90.

23. Yu YC, Koo ST, Kim CH, Lyu Y, Grady JJ, Chung JM. Two variables that can be used as pain indices in experimental animal models of arthritis. J Neurosci Methods 2002; 115: 107-13.

24. Skyba DA, Radhakrishnan R, Sluka KA. Characterization of a method for measuring primary hyperalgesia of deep somatic 
tissue. J Pain 2005; 6: 41-7.

25. Gong W, Johanek LM, Sluka KA. Spinal cord stimulation reduces mechanical hyperalgesia and restores physical activity levels in animals with noninflammatory muscle pain in a frequency-dependent manner. Anesth Analg 2014; 119: 18695.

26. da Silva MD, Guginski G, Werner MF, Baggio CH, Marcon R, Santos AR. Involvement of interleukin-10 in the anti-inflammatory effect of Sanyinjiao (SP6) acupuncture in a mouse model of peritonitis. Evid Based Complement Alternat Med 2011; 2011: 217946.

27. Sluka KA, Judge MA, McColley MM, Reveiz PM, Taylor BM. Low frequency TENS is less effective than high frequency TENS at reducing inflammation-induced hyperalgesia in morphine-tolerant rats. Eur J Pain 2000; 4: 185-93.

28. Ma YT, Sluka KA. Reduction in inflammation-induced sensitization of dorsal horn neurons by transcutaneous electrical nerve stimulation in anesthetized rats. Exp Brain Res 2001; 137: 94-102.

29. Matsuo H, Uchida K, Nakajima H, Guerrero AR, Watanabe S, Takeura N, et al. Early transcutaneous electrical nerve stimulation reduces hyperalgesia and decreases activation of spinal glial cells in mice with neuropathic pain. Pain 2014; 155: 1888-901.

30. Gibson W, Wand BM, Meads C, Catley MJ, O'Connell NE. Transcutaneous electrical nerve stimulation (TENS) for chronic pain - an overview of Cochrane Reviews. Cochrane Database Syst Rev 2019; 4: CD011890.

31. Nnoaham KE, Kumbang J. Transcutaneous electrical nerve stimulation (TENS) for chronic pain. Cochrane Database Syst Rev 2008; 3: CD003222.

32. Sluka KA, Bjordal JM, Marchand S, Rakel BA. What makes transcutaneous electrical nerve stimulation work? Making sense of the mixed results in the clinical literature. Phys Ther 2013; 93: 1397-402.

33. Cheing GL, Tsui AY, Lo SK, Hui-Chan CW. Optimal stimulation duration of tens in the management of osteoarthritic knee pain. J Rehabil Med 2003; 35: 62-8.

34. Johnson MI, Mulvey MR, Bagnall AM. Transcutaneous electrical nerve stimulation (TENS) for phantom pain and stump pain following amputation in adults. Cochrane Database Syst Rev 2015; 8: CD007264.

35. Jin DM, Xu Y, Geng DF, Yan TB. Effect of transcutaneous electrical nerve stimulation on symptomatic diabetic peripheral neuropathy: a meta-analysis of randomized controlled trials. Diabetes Res Clin Pract 2010; 89: 10-5.

36. Tokuda M, Tabira K, Masuda T, Nishiwada T, Shomoto K. Effect of modulated-frequency and modulated-intensity transcutaneous electrical nerve stimulation after abdominal surgery: a randomized controlled trial. Clin J Pain 2014; 30: 565-70.
37. Celik EC, Erhan B, Gunduz B, Lakse E. The effect of lowfrequency TENS in the treatment of neuropathic pain in patients with spinal cord injury. Spinal Cord 2013; 51: 334-7.

38. Yameen F, Shahbaz NN, Hasan Y, Fauz R, Abdullah M. Efficacy of transcutaneous electrical nerve stimulation and its different modes in patients with trigeminal neuralgia. J Pak Med Assoc 2011; 61: 437-9.

39. Vance CG, Rakel BA, Blodgett NP, DeSantana JM, Amendola A, Zimmerman MB, et al. Effects of transcutaneous electrical nerve stimulation on pain, pain sensitivity, and function in people with knee osteoarthritis: a randomized controlled trial. Phys Ther 2012; 92: 898-910.

40. Johnson M, Martinson M. Efficacy of electrical nerve stimulation for chronic musculoskeletal pain: a meta-analysis of randomized controlled trials. Pain 2007; 130: 157-65.

41. Sdrulla AD, Guan Y, Raja SN. Spinal cord stimulation: clinical efficacy and potential mechanisms. Pain Pract 2018; 18: 1048-67.

42. Buonocore M, Bonezzi C, Barolat G. Neurophysiological evidence of antidromic activation of large myelinated fibres in lower limbs during spinal cord stimulation. Spine (Phila $\mathrm{Pa}$ 1976) 2008; 33: E90-3.

43. Vallejo R, Bradley K, Kapural L. Spinal cord stimulation in chronic pain: mode of action. Spine (Phila Pa 1976) 2017; 42 Suppl 14: S53-60.

44. Cha MH, Choi JS, Bai SJ, Shim I, Lee HJ, Choi SM, et al. Antiallodynic effects of acupuncture in neuropathic rats. Yonsei Med J 2006; 47: 359-66.

45. Plaster R, Vieira WB, Alencar FA, Nakano EY, Liebano RE. Immediate effects of electroacupuncture and manual acupuncture on pain, mobility and muscle strength in patients with knee osteoarthritis: a randomised controlled trial. Acupunct Med 2014; 32: 236-41.

46. Goldman N, Chen M, Fujita T, Xu Q, Peng W, Liu W, et al. Adenosine $\mathrm{Al}$ receptors mediate local anti-nociceptive effects of acupuncture. Nat Neurosci 2010; 13: 883-8.

47. Norrbrink C, Lundeberg T. Acupuncture and massage therapy for neuropathic pain following spinal cord injury: an exploratory study. Acupunct Med 2011; 29: 108-15.

48. Berman BM, Singh BB, Lao L, Langenberg P, Li H, Hadhazy $\mathrm{V}$, et al. A randomized trial of acupuncture as an adjunctive therapy in osteoarthritis of the knee. Rheumatology (Oxford) 1999; 38: 346-54.

49. Witt C, Brinkhaus B, Jena S, Linde K, Streng A, Wagenpfeil S, et al. Acupuncture in patients with osteoarthritis of the knee: a randomised trial. Lancet 2005; 366: 136-43.

50. Vas J, Modesto M, Aguilar I, Santos-Rey K, Benítez-Parejo N, Rivas-Ruiz F. Effects of acupuncture on patients with fibromyalgia: study protocol of a multicentre randomized controlled trial. Trials 2011; 12: 59. 